\title{
Separation and Detection of Polychlorodibenzofurans (PCDFs) on Japanese Commercial PCBs (Kanechlors) and Their Heated Preparation
}

(Received October 23, 1975)

\author{
Hideaki Miyata*, Akio Nakamura* and Takashi Kashimoto* \\ (*Osaka Prefectural Institute of Public Health: \\ 1-3-69, Nakamichi, Higashinari-ku, Osaka)
}

\begin{abstract}
Modified analytical methods by $\operatorname{Vos}^{1)}$ and Poter et $a .^{2)}$ were used for the separation of polychlorodibenzofurans (PCDFs) from Japanese commercial PCBs (Kanechlors) which were used in large quantities in Japan. Di, tri, tetra, penta, hexa and heptachlorodibenzofurans were detected on Kanechlors by GC-MS analysis. Total PCDF concentrations were 9, 33, 4 and 4 ppm in Kanechlor 300 (KC-300), Kanechlor 400 (KC-400), Kanechlor 500 (KC-500) and Kanechlor 600 (KC-600), respectively. In addition, to investigate the possibility that PCDFs were formed during the usage of PCB as heat transfer medium, $\mathrm{KC}-400$ was put into a pyrexglass ample and heated on a gas chromatograph oven. However, PCDFs did not generate by heating for 15 days at $300^{\circ} \mathrm{C}$.
\end{abstract}

\section{Introduction}

In 1970, Vos et al. ${ }^{1)}$ reported that very toxic polychlorodibenzofurans (PCDFs) were found in German and French PCB preparations. The toxicity of pure PCDFs has not been thoroughly investigated but appeared to be extraordinary high. Tri and tetrachlorobenzofuran in single oral dose of $0.5-1.0 \mathrm{mg} / \mathrm{kg}$ caused severe and often lethal liver necrosis in rabbits ${ }^{3}$ ). PCDF (principally pentachlorodibenzofuran) induced the hepatic microsomal oxygenating enzyme 170 times stronger than Japanese commercial PCB containing $40 \%$ chlorine (Kanechlor 400). ${ }^{4)}$ If PCDFs are present in commercial PCBs, they may be accumulated in human bodies through food chains. In 1970, we traced the method of Vos et al. on Japanese commercial PCB containing $60 \%$ chlorine (Kanechlor 600) and, in consequence, found that the final fraction, PCDF fraction in the method of Vos et al., caused extremely strong lethal effect on chick embryos, although the amount of that fraction was as little as one fifty-thousandth of original Kanechlor 600 . However, GC-MS analysis revealed that the final fraction was mainly composed of tri to hepta chlorinated biphenyls and hepta to octa chlorinated naphthalenes but not PCDFs. In the present report, we could enable the better isolation and recovery of PCDFs from PCBs than the method of Vos et al. Accordingly the actual concentration of total PCDFs was determined. Moreover, the possibility of the generation of PCDFs during the usage of PCB as heat transfer medium was tested.

\section{Materials and methods}

\subsection{Kanechlor preparation}

Kanechlor preparations (KC-300, KC-400, KC500 and $\mathrm{KC}-600$ ) were distributed to our laboratory in 1972 by the Ministry of Health and Welfare.

\subsection{Reagents}

Polychlorodibenzofuran preparation containing 46.3-56.8\% chlorine was obtained from Wako Pure Chemical Co. Ltd. Florisil was 60-80 mesh and activated overnight at $130^{\circ} \mathrm{C}$. Alumina was obtained from Merck Co. Ltd., No. Art. 1077. n-hexane, acetone, methylene dichloride and ethyl ether were reagent grade for PCB analysis, Wako Pure Chemical or Katayama Chemical Co. Ltd.

\subsection{Separating method of PCDFs from PCBs}

a) Florisil column chromatography

The isolation procedure was the modified method of Vos et al. ${ }^{1)}$ Florisil (180 g) was packed with $\mathrm{n}$-hexane in a $3.5 \mathrm{~cm}$ i.d. glass column. Before the application of PCB on the column, florisil column was prewashed with about $500 \mathrm{ml}$ of $\mathrm{n}$-hexane. A half to one gram of PCB dissolved in $50 \mathrm{ml}$ of $\mathrm{n}$ hexane was added into a column, and the all of the column was rinsed with $50 \mathrm{ml}$ of $\mathrm{n}$-hexane. The column was then eluted with the following three eluants successively at a rate of about $15 \mathrm{ml} / \mathrm{min}$. 
Eluants were $1700 \mathrm{ml}$ of $\mathrm{n}$-hexane, $1000 \mathrm{ml}$ of $5 \%$ ethyl ether-n-hexane and $1500 \mathrm{ml}$ acetone.

b) Alumina column chromatography

The procedure is similar to that outlined by Poter et al. $^{2)}$. Acetone fraction mentioned above was concentrated by rotary evaporator, dried under a stream of air, and dissolved with $3 \mathrm{ml}$ of methylene chloride-n-hexane before an application on alumina column. Alumina $(20 \mathrm{~g})$ was packed with $\mathrm{n}$-hexane in a $2 \mathrm{~cm} i . d$. glass column and was prewashed with $50 \mathrm{ml}$ of $\mathrm{n}$-hexane. Sample was then added to the column and eluted successively with $200 \mathrm{ml}$ of $3 \%$ methylene chloride-n-hexane and $200 \mathrm{ml}$ of $20 \%$ methylene chloride-n-hexane. Small quantity of PCBs eluted with acetone from the florisil column was removed by $3 \%$ methylene chloride-n-hexane washing. PCDFs, polychlorodibenzo-p-dioxine and more polar compounds were eluted in the fraction of $20 \%$ methylene chloride-n-hexane effluent, which was named as the PCDF fraction.

\subsection{Analysis of the PCDF fraction}

Gas chromatography-mass spectrometry (GCMS) was used to identify compounds present in the PCDF fraction. GC-MS analysis were carried out on a Shimadzu LKB-9000 GC-MS. Conditions: $2 \mathrm{~m} \times 3 \mathrm{~mm}$ glass column packed with $1.5 \% \mathrm{OV}-17$ on Cromosorb W (80-100 mesh); injection temp., $300^{\circ} \mathrm{C}$; column temp., programmed from 200 to $280^{\circ} \mathrm{C}\left(3^{\circ} \mathrm{C} / \mathrm{min}\right.$. $)$. MS condition: Ionizing voltage,
$70 \mathrm{eV}$; accel. voltage, $3.5 \mathrm{kV}$; chamber temp., $320^{\circ} \mathrm{C}$. For the determination of PCDF, GC analysis was carried out using Varian Aerograph Model 2100 equipped with ${ }^{63} \mathrm{Ni}-\mathrm{ECD}$. GC conditions: $1.8 \mathrm{~m} \times 2 \mathrm{~mm}$ glass column packed with $2 \% \mathrm{OV}-17$ on Gaschrom Q (100-120 mesh); injection temp., $200^{\circ} \mathrm{C}$; detector temp., $305^{\circ} \mathrm{C}$; column tem., programmed from 180 to $300^{\circ} \mathrm{C}\left(4^{\circ} \mathrm{C} / \mathrm{min}\right.$.); carrier gas, $\mathrm{N}_{2}(20 \mathrm{ml} / \mathrm{min}$.).

\subsection{Heat treatment of $\mathrm{KC}-\mathbf{4 0 0}$}

$\mathrm{KC}-400(2.6 \mathrm{ml})$ was poured into $8 \mathrm{~cm} \times 1.5 \mathrm{~cm}$ $i$. $d$. pyrex glass amples. After sealing, they were heated in a gas chromatograph oven for various periods under different temperature indicated in Table 3. Heated $\mathrm{KC}-400$ was analyzed according to above procedure, and the formation of PCDFs was investigated.

\section{Results}

\subsection{PCDFs in Kanechlors}

As shown in Table 1, mass spectrometric analysis revealed that di, tri, tetra, penta, hexa and heptachlorodibenzofurans were present in the PCDF fraction from Kanechlors. The concentration of total PCDFs in KC-300, KC-400, KC-500 and KC-600 was 9, 33, 4 and 4 ppm, respectively.

Dichlorobenzofurans were detected only in the PCDF fraction from KC-400. As a rule, chlorine content of PCDFs tended to increase in proportion to chlorine content of Kanechlor, e. g. main PCDFs

Table 1. Component and Concentration of PCDF in Kanechlors

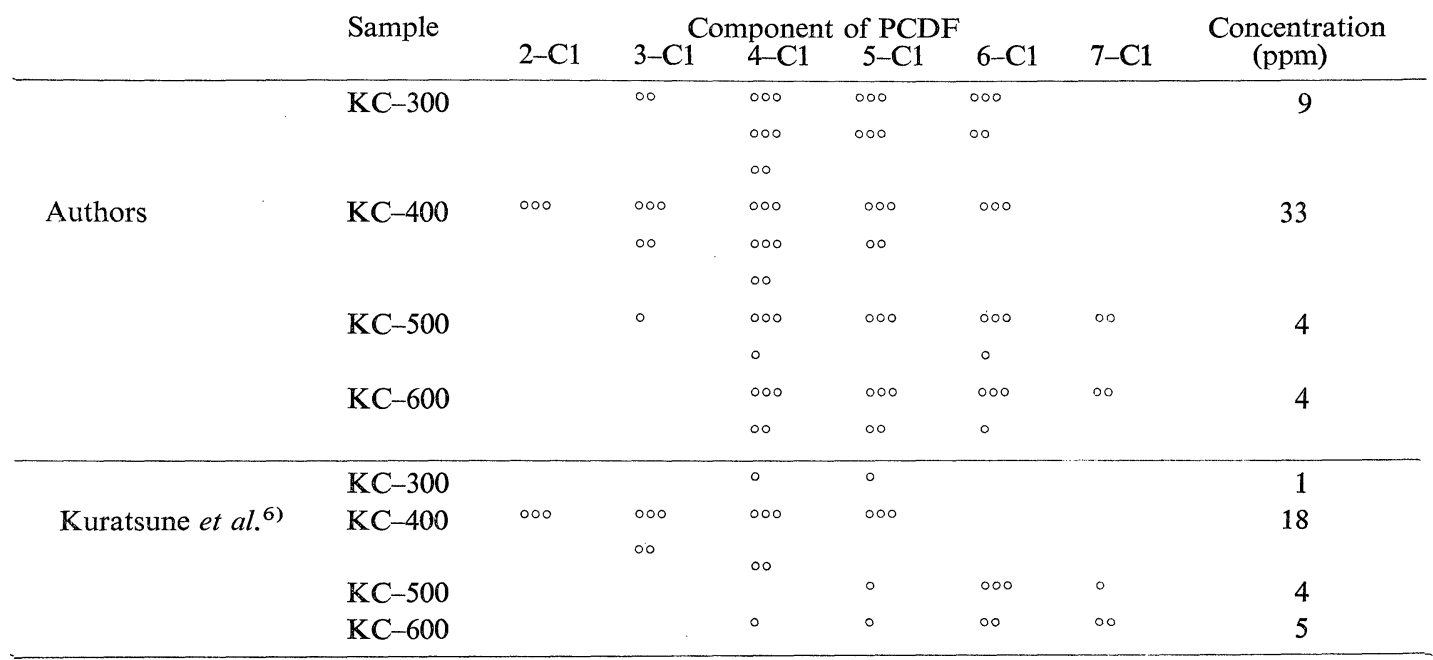

Roach et al. ${ }^{5)} \quad \mathrm{KC}-400 \quad 2,3$ and 4-C1 PCDF were found, but number of PCDF component was not described in their paper

4-C1 PCDFs were $1 \mathrm{ppm}$

$\circ$ Indicates individual component 


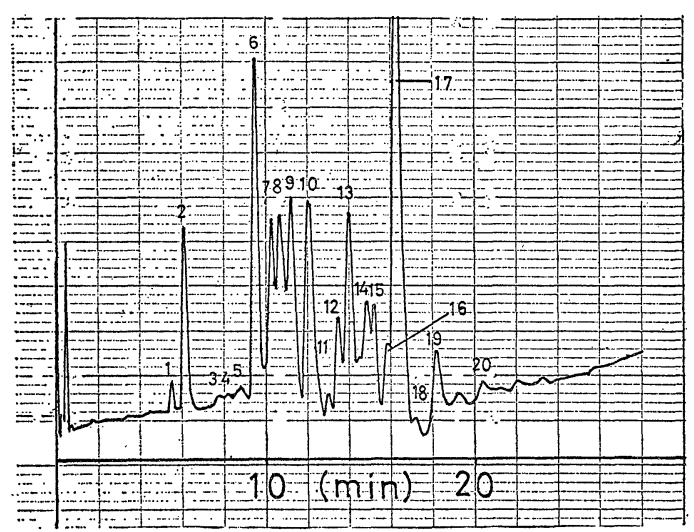

Fig. 1. Gas chromatogram of the PCDF fraction from $\mathrm{KC}-400$

obtained from $\mathrm{KC}-300$ were tri and tetrachlorodibenzofuran isomers, and $\mathrm{KC}-600$ contained penta and hexa chloro-derivatives. The electron capture gas chromatogram of the PCDF fraction obtained from $\mathrm{KC}-400$ were shown in Fig. 1, and mass spectrometric deta of peaks shown in Fig. 1 were listed in Table 2.

The mass spectra of peaks 5, 9 and 15 in Fig. 1 were given in Fig. 2 (a, b and c, respectively). Peaks 5, 9 and 15 were identified as tri, tetra and penta-
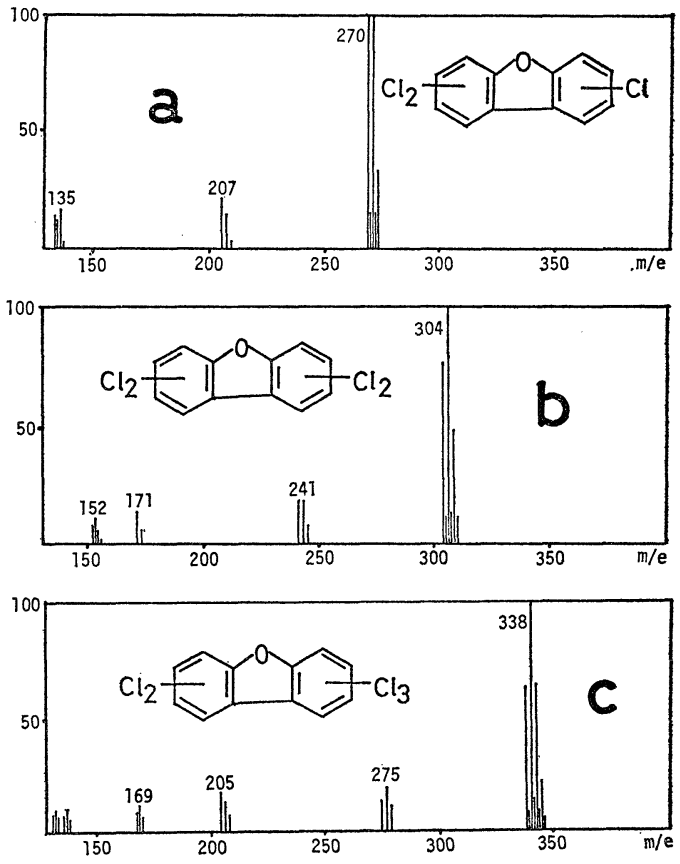

Fig. 2. Mass spectra of peak 5, 9 and 15 in Fig. 1 a, peak 5 ; b, peak 9 ; c, peak 15 .

chlorodibenzofuran, respectively. Tetrachlorobenzofuran fragments were as follows (cf. Fig.

Table 2. Identification of Peaks appeared in Fig. 1

Peak No.

Compound

$\begin{array}{rll}1 & \text { 2-C1 } & \text { PCDF (main), DBP } \\ 2 & 3-\mathrm{C} 1 & \text { PCB (main), 4-C1 PCB } \\ 3 & 3-\mathrm{C} 1 & \text { PCDF } \\ 4 & 3-\mathrm{C} 1 & \text { PCDF } \\ 5 & 3-\mathrm{C} 1 & \text { PCDF } \\ 6 & 4-\mathrm{C} 1 & \text { PCB (main), 3-C1 PCB, 3-C1 PCDF } \\ 7 & 4-\mathrm{C} 1 & \text { PCDF (main), 4-C1 PCB } \\ 8 & 4-\mathrm{C} 1 & \text { PCDF (main), 4-C1 PCB } \\ 9 & \text { 4-C1 } & \text { PCDF } \\ 10 & \text { 4-C1 } & \text { PCDF } \\ 11 & \text { 4-C1 } & \text { PCDF (main), 4-C1 PCB } \\ 12 & \text { 4-C1 } & \text { PCDF, 5-C1 PCDF, Monomethyl 5-C1 PCN } \\ 13 & \text { 4-C1 } & \text { PCDF, 5-C1 PCDF, 6-C1 PCN } \\ 14 & 5-\mathrm{C} 1 & \text { PCDF (main), Monomethyl 5-C1 PCN } \\ 15 & 5-\mathrm{C} 1 & \text { PCDF } \\ 16 & 5-\mathrm{C} 1 & \text { PCDF, Monomethyl 5-C1 PCN } \\ 17 & 7-\mathrm{C} 1 & \text { PCN } \\ 18 & \text { 6-C1 } & \text { PCDF } \\ 19 & \text { 6-C1 } & \text { PCDF } \\ 20 & \text { 6-C1 } & \text { PCDF }\end{array}$

Peak No., Correspond to number indicated in Fig. 1; PCDF, Polychlorodibenzofuran; PCN, Polychloronaphthalene; DBP, Dibuthyl phthalate. 
Table 3. Color of Heated KC-400 and PCDF Concentration in It

\begin{tabular}{cclc}
$\begin{array}{c}\text { Heating temp. } \\
\left({ }^{\circ} \mathrm{C}\right)\end{array}$ & $\begin{array}{c}\text { Heating period } \\
(\text { day })\end{array}$ & \multicolumn{1}{c}{ Color } & $\begin{array}{c}\text { PCDF concent. } \\
(\mathrm{ppm})\end{array}$ \\
\hline Room temp. & 0 & Colorless & 33 \\
180 & 5 & Light yellow & 42 \\
250 & 5 & Yellow & 40 \\
300 & 5 & Brown & 35 \\
300 & 10 & Brown & 35 \\
300 & 15 & Dark brown & 40
\end{tabular}

2-b): the molecular ion $\left(\mathrm{M}^{+}\right)$was found at $\mathrm{m} / \mathrm{e} 304$, loss of $\mathrm{COCl}$ yielded the peak at $\mathrm{m} / \mathrm{e} 241$, subsequent elimination of double $\mathrm{Cl}$ resulted of in $\mathrm{m} / \mathrm{e}$ 171. the tri and pentachlorodibenzofuran fragments were identified in an analogous fashion as described above.

\subsection{Heat treatment of $\mathrm{KC}-400$}

As shown in Table 3, the color of $\mathrm{KC}-400$ turned from light yellow to dark brown with rising of temperature. When $\mathrm{KC}-400$ was heated at $300^{\circ} \mathrm{C}$, its color turned to brown within only an hour. However, electron capture GC analysis revealed that heated PCB and PCDFs in it didn't change both qualitatively and quantitatively (Table 2).

\section{Discussion}

Until recent days, there was no report about PCDFs in Kanechlors. In 1974, Roach et al. ${ }^{5)}$ reported first that di, tri and tetrachlorodibenzofurans presented in $\mathrm{KC}-400$. In the present study, we found di, tri, tetra, penta, hexa and heptachlorodibenzofurans in $\mathrm{KC}-300, \mathrm{KC}-400, \mathrm{KC}-500$ and KC-600. Kuratsune et al. ${ }^{6)}$ also confirmed the presence of PCDFs in Kanechlors. On the constituent and the concentration of PCDFs on Kanechlors except $\mathrm{KC}-300$, our result was similar to the report by Kuratsune et al. Although Kuratsune et al. reported that tetra and pentachlorodibenzofurans were present in $\mathrm{KC}-300$ in a concentration of $1 \mathrm{ppm}$, we found that 18 kinds of chlorodibenzofurans having three to six chlorines in a molecule were present in $\mathrm{KC}-300$ in a concentration of 9 $\mathrm{ppm}$. Such difference of concentration and composition of PCDF may attributed to the difference of lots or analytical methods. In 1975, Kuratsune et $a{ }^{6}{ }^{6)}$ found approximately $5 \mathrm{ppm}$ PCDFs in "Kanemi Rice Oil". PCB concentration was about 1000 ppm in "Kanemi Rice Oil," so the concentration of PCDF was supposed approximately as 5000 ppm in $\mathrm{KC}-400$ which was leaked out into "Kanemi Rice Oil". So, it is said that PCDFs are one of the compounds caused "Kanemi Yusho". However, the question arised whether such high amount of PCDFs would be present as concentration in $\mathrm{KC}-400$ or would be produced during the period used as heat transfer medium. To dissolve this question, $\mathrm{KC}-400$ sealed in amples were heated in gas chromatograph oven, but no PCDF generated by this condition. PCDFs may generate under longer heating period, higher heating temperature of addition of catalysts. Further investigations are under way.

\section{Acknowledgement}

We thank Mr. Takahashi, Shimadzu Seisakusho Ltd., for assistance with the GC-MS.

\section{References}

1) Vos, J. G., Koeman, J. H., Mass, H. L., Brauw, M. C., Vos, R. H.: Fd. Cosmet. Toxicol , 8, 625 (1970).

2) Poter, M. L., Burke, J. A.: J. Anal. Offic. Assoc. Chem., 54, 1426 (1971).

3) Shultz, B. H., Spiegelberg, K. H.: Arch. Gewerbepath. Gewebehyg., 18, 583 (1961).

4) Araki, Y.: Fukuoka Acta Medica, 65, 61 (1974).

5) Roach, J. A. G., Pomerantz, I. H.: Bull. Enviro. Contam. Toxicol., 12, 338 (1974).

6) Nagayama, J., Masuda, Y., Kuratsune, M.: Jap. J. Hyg., 30, 126 (1975). 